\title{
Transient Creep and Creep Recovery Behaviour of Cu-2wt\%Sn Alloy Near the Transformation Temperature
}

\author{
G. S. Al-Ganainy ${ }^{1}$ and M. M. Mostafa ${ }^{2}$ \\ ${ }^{1}$ Department of Physics, Faculty of Science, Ain Shams University, \\ Cairo, Egypt \\ 2 Department of Physics, Faculty of Education, Ain Shams University, \\ Cairo, Egypt
}

In this work the transient creep, creep recovery and the structure of $\mathrm{Cu}-2 w t \%$ Sn alloy have been investigated. These investigations are conducted in the temperature range, $190-280{ }^{\circ} \mathrm{C}$, under various constant stresses of 258 , 322.4 and $386.9 \mathrm{MPa}$. All the creep and creep recovery parameters show two distinct regions in the used deformation temperature range and confirm a transition point at $240{ }^{\circ} \mathrm{C}$ for the examined alloy. The energy activating the transient creep is calculated. The lattice parameter for the cubic copper phase has a minimum value at $240{ }^{\circ} \mathrm{C}$. The best estimate of the transient creep parameters ( $n$ and $\beta$ ) as well as the activation energy of creep process $(Q)$ are obtained using the least- squares method.

\section{Introduction:}

The high technological applications of $\mathrm{Cu}$-based alloys in industry are owing to their excellent strength, corrosion resistance, thermal and electrical conductivity and the ability of joining in industry [1]. The components and plants of these materials are easily assembled by the proper and conventional brazing and welding. Therefore, they have been developed for using as the lead wire materials in diodes and transistors and the lead fram materials in the integrated circuits [2]. The creep behavior of some $\mathrm{Cu}$ alloys has been investigated [3- 6]. The dependence of creep and creep recovery on the microstructure of the test materials was previously studied [7-10]. The transient creep behaviour of $\mathrm{Cu}-10 \mathrm{wt} \% \mathrm{Sn}$ alloy [4] was studied in the solid solution temperature range $\left(375-475{ }^{\circ} \mathrm{C}\right)$. The results of the transient creep parameter $\beta$ yielded an activation energy of grain boundary sliding or migration. The previous investigations $[3,11]$ showed that $\mathrm{Sn}$ has a good affinity of segregation into the grain boundaries of $\mathrm{Cu}$. This brings strain to a time independent 
phenomenon and so prevents the harmful creep process. Also, the precipitation of $\mathrm{Sn}$ on the grain boundaries of $\mathrm{Cu}$ blocks their motion and so prevents grain growth. This leads to a required stability in the mechanical properties of the product under given work condition. This is why the $\mathrm{Cu}-\mathrm{Sn}$ alloy was chosen for study in the present work. Moreover, little information known about the transient creep and creep recovery around the transformation temperature of $\mathrm{Cu}$ $2 \mathrm{wt} \% \mathrm{Sn}$ alloy. Therefore, the present investigation for this alloy is initiated in order to elucidate further the effect of thermal phase transformation on the transient creep and creep recovery parameters of this alloy in the temperature range $190-280{ }^{\circ} \mathrm{C}$.

The best estimate of the transient creep parameters (n and $\beta$ ) as well as the activation energy of creep process $(\mathrm{Q})$ are obtained using a least squares method.

\section{Experimental details:}

The purity of the starting materials is $99.99 \%$ for copper and $99.999 \%$ for tin. The nominal composition $\mathrm{Cu}-2 \mathrm{wt} \% \mathrm{Sn}$ was chosen for the present study. The alloy was produced by melting the pre-weighted materials in a graphite crucible and chill casting. The cast rod was homogenized by annealing at 200 ${ }^{\mathrm{O}} \mathrm{C}$ for $40 \mathrm{~h}$ then swaged in wire form of diameter $0.44 \mathrm{~mm}$. Wire samples of length $30 \mathrm{~mm}$ were annealed at $310{ }^{\circ} \mathrm{C}$ for $2 \mathrm{~h}$ then slowly cooled to room temperature with a cooling rate of $7.7 \times 10^{-3}{ }^{\circ} \mathrm{C} / \mathrm{s}$. After this heat treatment, a second phase was considered to be precipitated in the samples.

Creep experiments were performed using a locally made machine. The creep tests of the prepared samples were conducted under various constant applied stresses of $258,322.4$ and $386.9 \mathrm{MPa}$ at constant temperature ranging from 190 to $280{ }^{\circ} \mathrm{C}$. The temperature could be maintained to within $\pm 2{ }^{\circ} \mathrm{C}$ inside the used furnace which contains a temperature uniformity part. The temperature uniformity through the part occupied by the specimen was better than $\pm 1{ }^{\circ} \mathrm{C}$. A dial gauge with an accuracy of $\pm 1 \mu \mathrm{m}$ was used to measure the extension in the wires during creep tests.

A Philips X-ray diffractometer (X'Pert) with $\mathrm{Cu}-\mathrm{K} \alpha$ radiation was used to obtain the diffraction patterns of the wire samples deformed under a stress of 386.9 MPa. These diffraction patterns were used to examine the microstructure of the samples and to calculate the lattice parameter of the $\mathrm{Cu}$-phase. 


\section{Results:}

Figure 1 shows some representative examples of the creep and creep recovery curves for wire samples of the present alloy tested in the temperature range $190-280{ }^{\circ} \mathrm{C}$ in steps of $10{ }^{\circ} \mathrm{C}$. The creep recovery test of the samples is obtained by sudden release of the applied stress when the sample has undergone tensile creep deformation. The total recovery strain rate $\tau^{\bullet}$ and the percentage residual strain ratio $\gamma$ are determined as;

$$
\begin{aligned}
& \tau^{\cdot}=\left(\varepsilon_{\text {tot }}-\varepsilon_{\text {resd.tot }}\right) / \mathrm{t}_{\mathrm{r}}=\tau_{\text {tot }} / \mathrm{t}_{\mathrm{r}} \\
& \gamma=\left[\left(\varepsilon_{\text {tot }}-\tau_{\text {tot }}\right) / \varepsilon_{\text {tot }}\right] \%
\end{aligned}
$$

where $\tau_{\text {tot }}$ is the relaxed strain and $t_{r}$ is the relaxation time.

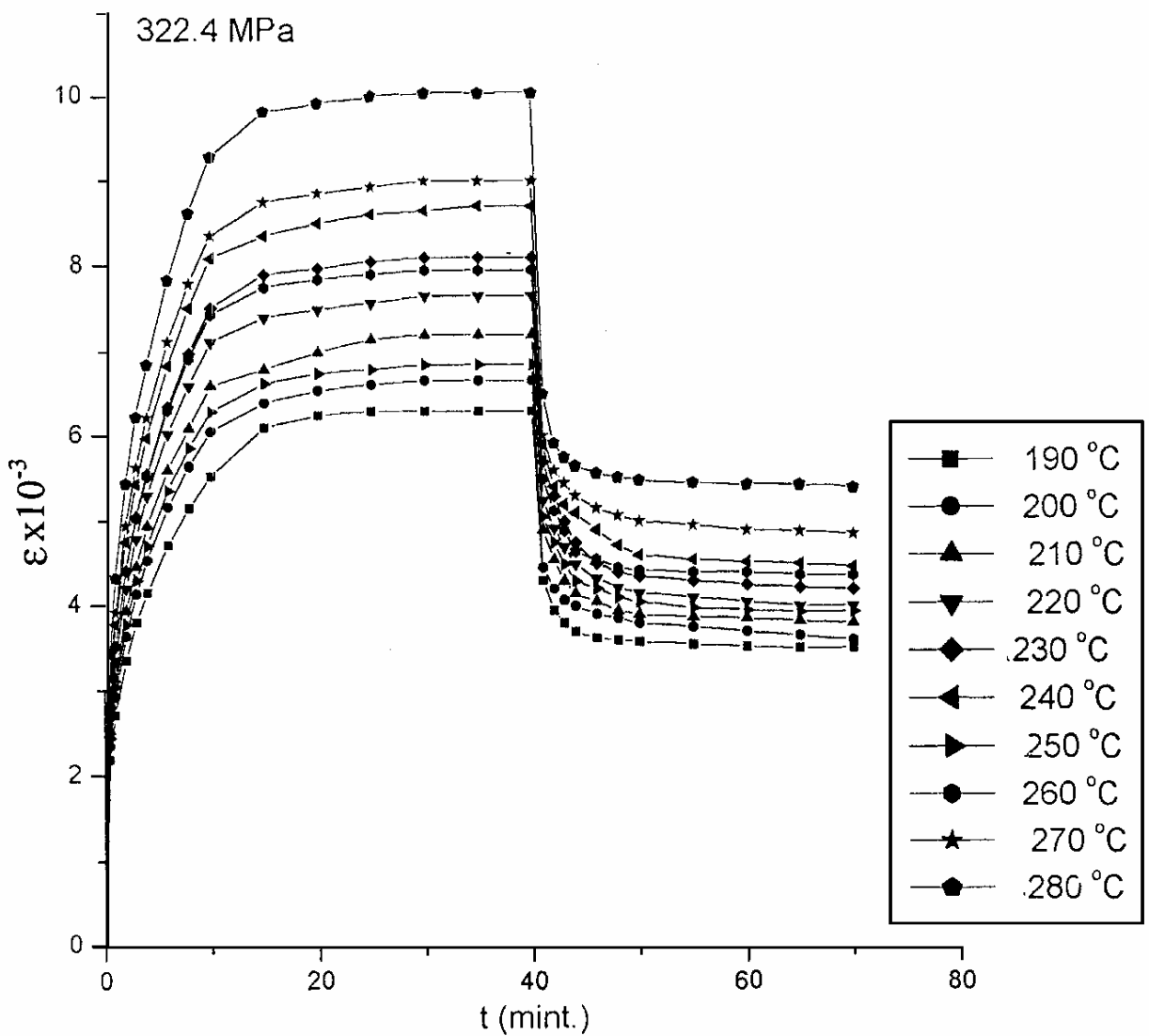

Fig.(1): A representative group of isothermal creep and creep recovery curves for samples of $\mathrm{Cu}-2 \mathrm{wt} \% \mathrm{Sn}$ alloy deformed under $322.4 \mathrm{MPa}$. 
The straight lines plotted in Fig.(2) are obtained from the best fitting equations for the relation between the logarithm of the experimental transient strain, $\ln \varepsilon_{\text {tr }}$, against the logarithm of the transient creep time, $\ln t$ at each testing temperature. These linear relations have strong positive correlation coefficients $(>0.99)$ for all the test conditions and indicate that the transient creep of $\mathrm{Cu}$ $2 \mathrm{wt} \% \mathrm{Sn}$ alloy can be described by eq. $[4,12]$

$$
\varepsilon_{\mathrm{tr}}=\beta \mathrm{t}^{\mathrm{n}}
$$

where $n$ and $\beta$ are the transient creep parameters. A least-squares method computer program is used to get these parameters. $\mathrm{n}$ and $\beta$ are determined from the slopes and the intercepts of the straight lines in Fig.(2) respectively. Figure 3 represents the temperature dependence of the parameters $n$ and $\beta$. They are found to exhibit values ranging from 0.3065 to 0.3315 for $\mathrm{n}$ and from $6.856 \times 10^{-4}$ to $11.952 \times 10^{-4}$ for $\beta$ both with maxima clearly appear at $240{ }^{\circ} \mathrm{C}$ for all the applied stresses.

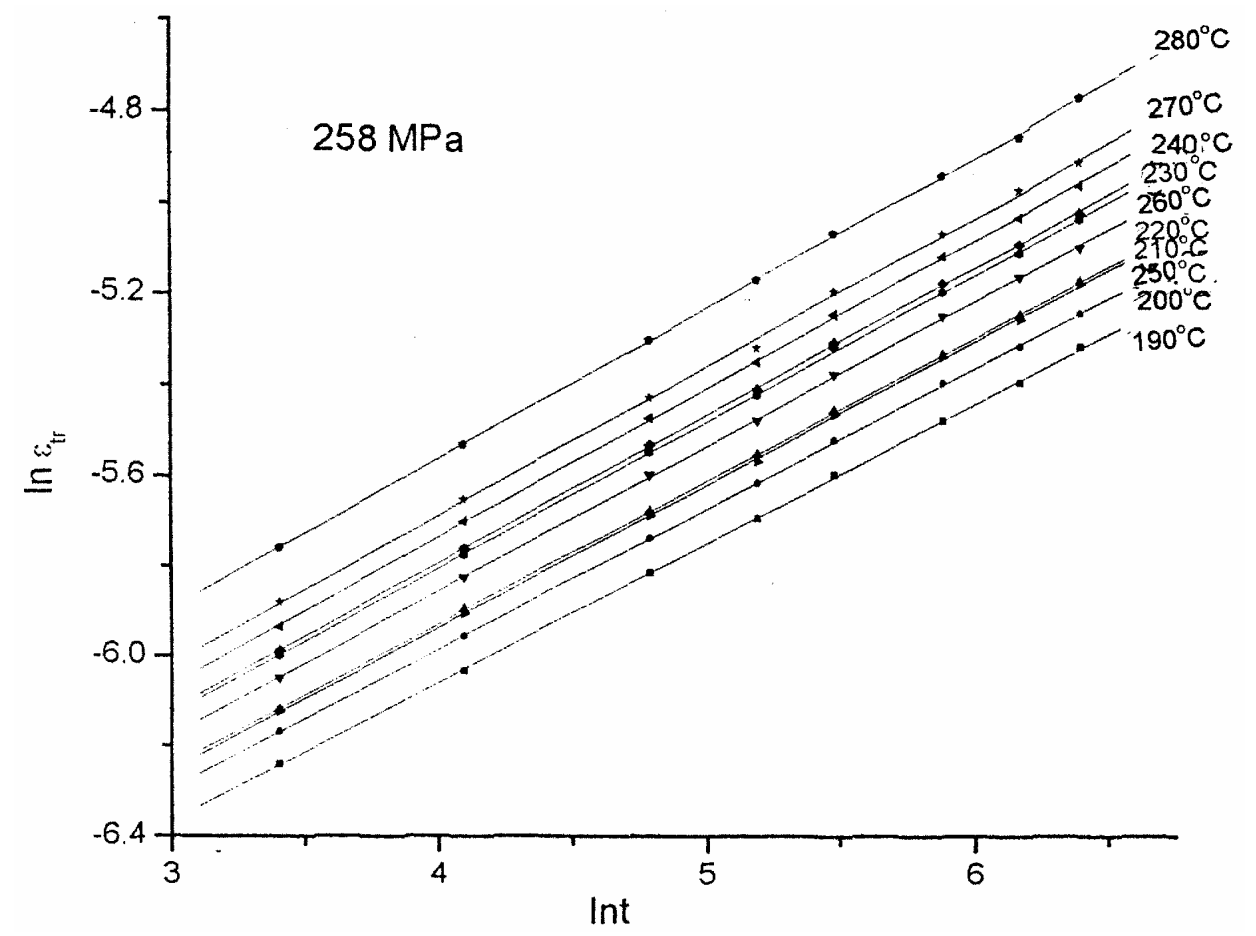

Fig.(2): A representative group of the best fitted straight lines resulting from the relation between $\ln \varepsilon_{\mathrm{tr}}$ and $\ln \mathrm{t}$. 
The activation enthalpy of the transient creep Q is calculated using the following equation [13]

$$
\varepsilon_{\mathrm{tr}}=\varepsilon_{\circ}+\mathrm{t}^{\mathrm{n}} \exp (-\mathrm{Q} / \mathrm{KT})
$$

where $\varepsilon_{\circ}$ is the instantaneous strain, $\mathrm{K}$ is Boltzman constant and $\mathrm{T}$ is the absolute temperature. So, in order to get the energy activating the transient creep process $\mathrm{Q}$, the relation between $\ln \beta$ and $1 / \mathrm{T}$ for each applied stress is fitted using a least- squares method (see Fig.4.). It can be seen that for each applied stress, this relation has two different linear forms of correlation coefficient $(<-0.99)$.
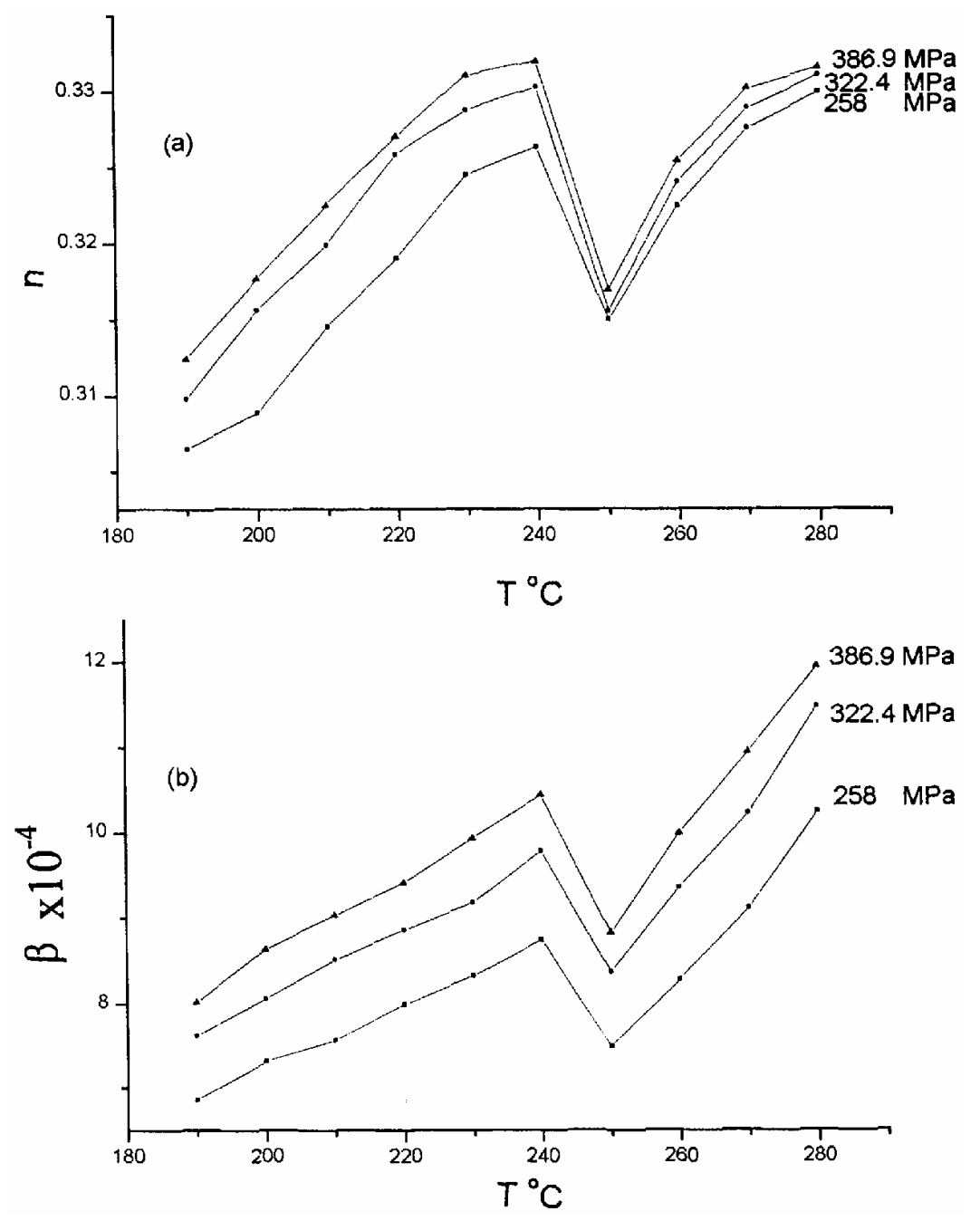

Fig.(3): The temperature dependence of the transient creep parameters a) $n$, and b) $\beta$ 
The slopes of these straight lines yield activation energy values of 9.4, 9.5 and $10.1 \mathrm{~kJ} / \mathrm{mol}$ for the applied stresses $258,322.4$ and $386.9 \mathrm{MPa}$, respectively, in the low temperature range (190- $240{ }^{\circ} \mathrm{C}$ )(Fig.4a). It has values of 25.2, 25.1 and $24.3 \mathrm{~kJ} / \mathrm{mol}$ for the same sequence of applied stresses in the high temperature range $\left(250-280{ }^{\circ} \mathrm{C}\right)$ (Fig. 4b). These results indicate that the activation energy is slightly affected by the applied stress and has average values of $(9.7 \pm 0.4)$ and $(24.9 \pm 0.5) \mathrm{kJ} / \mathrm{mol}$ in the low and high temperature ranges, respectively.
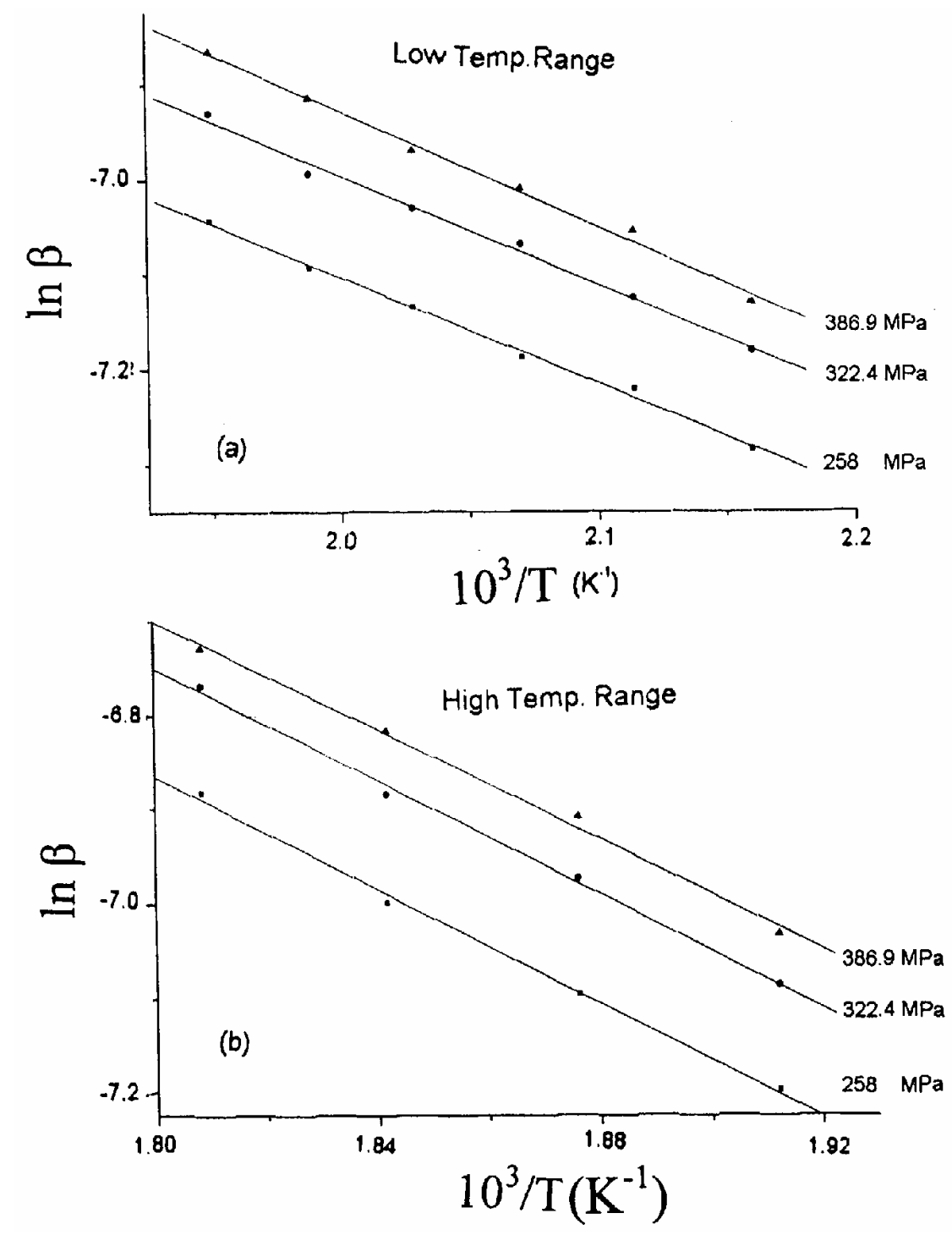

Fig.(4): The straight lines obtained from the best fitting equation for the relation between $\ln \beta$ and 1/T. 
Figure $5(\mathrm{a}, \mathrm{b}$ and $\mathrm{c})$ depicts the temperature dependence of the total tensile strain rate, $\dot{\varepsilon}_{\text {tot }}$, the total residual strain, $\varepsilon_{\text {resd.tot }}$ and the total recovery strain rate $\tau_{\text {tot. }}^{*}$ The values of these parameters increase with increasing the applied stress and show the existence of peaks in their curves for all the applied stresses at $240{ }^{\circ} \mathrm{C}$.
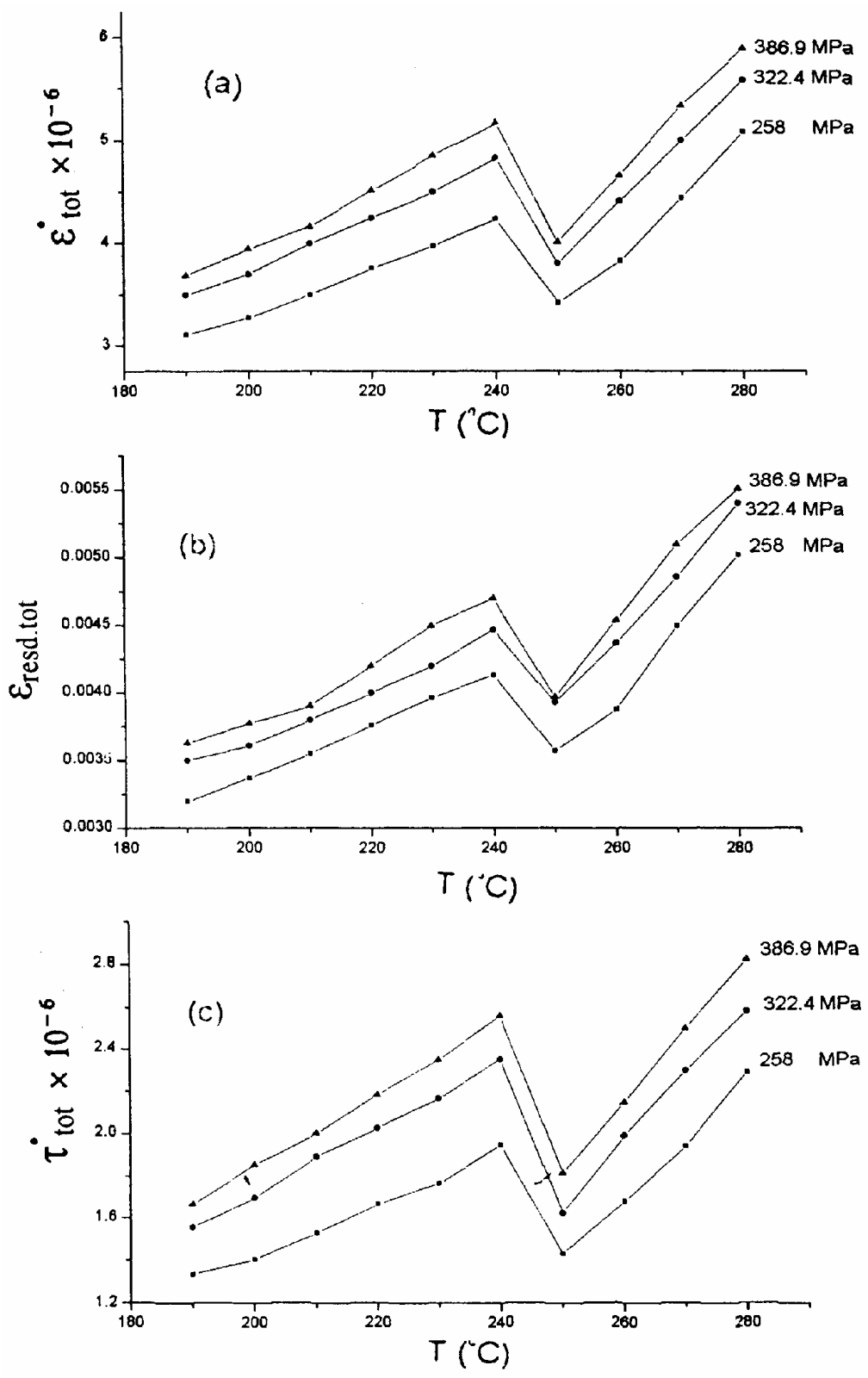

Fig.(5): The variations of a) $\varepsilon_{\text {tot, }}$ b) $\varepsilon_{\text {resd.tot }}$, c) $\tau_{\text {tot }}^{\cdot}$ with the working temperature. 
The changes in the percentage residual strain ratio $\gamma$ and the relaxation rate ratio $\chi\left(=\tau_{\text {tot }}{ } / \varepsilon_{\text {tot }}\right)$ with the testing temperature are illustrated in Fig. 6a and b, respectively. Pronounced minima and maxima appeare at $240{ }^{\circ} \mathrm{C}$ for $\gamma$ and $\chi$, respectively.
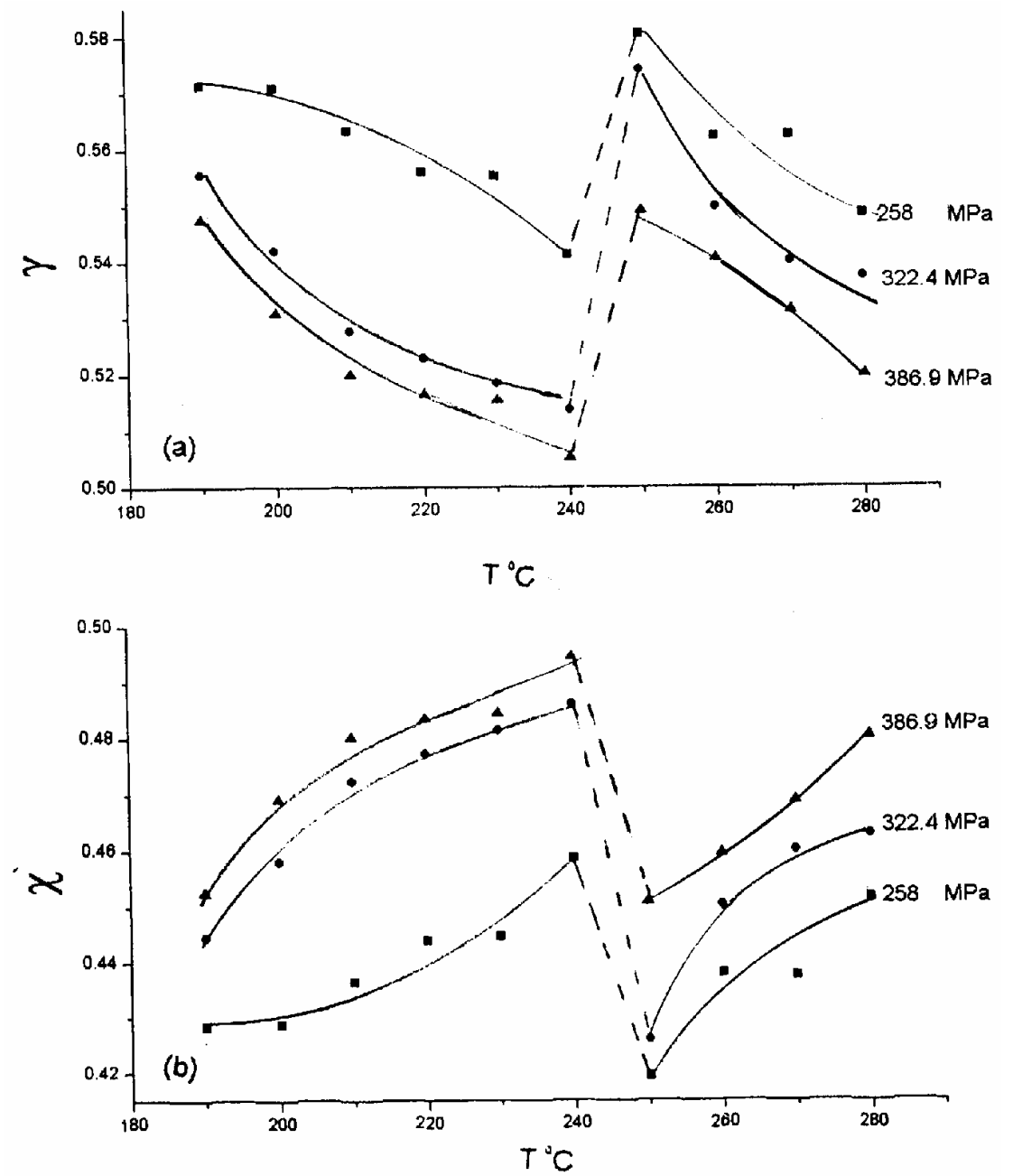

Fig.(6): The temperature dependence of

a) The residual strain ratio $\gamma, \quad$ b) The relaxation rate ratio $\chi$.

Representative examples for some X-ray diffraction patterns are shown in Fig.7. The lattice parameter, a, of the $\mathrm{Cu}$-phase is found to change with the deformation temperature. Its variation with temperature shown in Fig. 8 exhibits a maximum value at $240{ }^{\circ} \mathrm{C}$. 
The variations of all the measured parameters with temperature show a pronounced change in each of them at $240{ }^{\circ} \mathrm{C}$. This means that the same mechanism is responsible for the changes of both transient creep and creep recovery processes.

\section{Discussion:}

The analyses of the X-ray diffraction patterns for the undeformed and deformed $\mathrm{Cu}-2 \mathrm{wt} \% \mathrm{Sn}$ alloy samples in the low temperature range (below $240^{\circ} \mathrm{C}$ ) (Fig. 7) reveal the existence of the major $\mathrm{Cu}$ - phase and also the intermetallic compound $\varepsilon\left(\mathrm{Cu}_{3} \mathrm{Sn}\right)$ phase. These results coincide with the phases present in the binary $\mathrm{Cu}-\mathrm{Sn}$ system [14]. As the temperature is raised the dissociation process of the $\varepsilon$-phase to $\mathrm{Cu}$ and $\mathrm{Sn}$ atoms increases. The $\mathrm{X}$-ray diffraction patterns of the samples deformed at temperatures higher than $240{ }^{\circ} \mathrm{C}$ (Fig.7c) indicate that they consist of only the $\alpha$ - solid solution phase. The structural variations taking place in the examined samples in the phase transformation temperature range are the mainly effective reasons for the changes of the creep and creep recovery parameters.

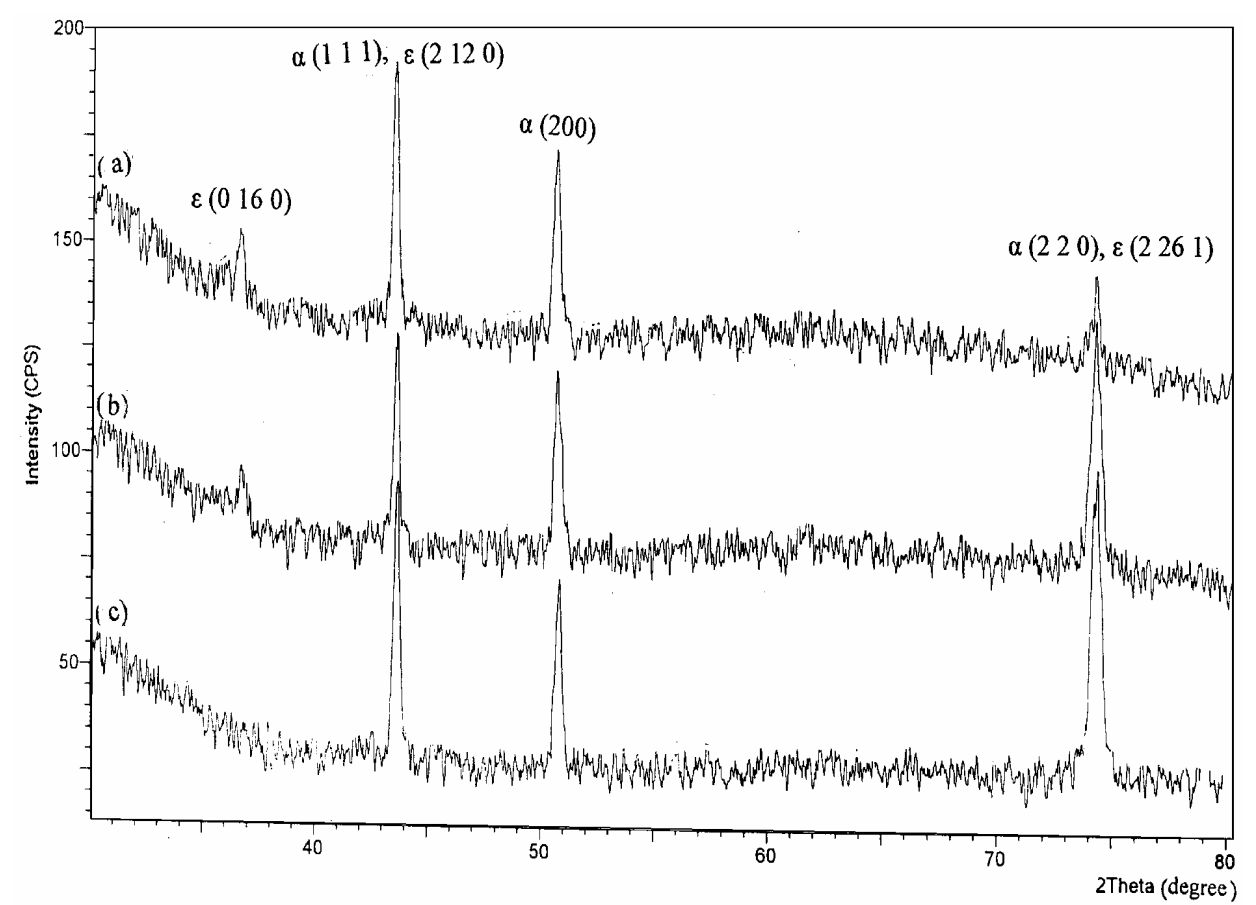

Fig.(7): Representative example of x-ray diffraction patterns for;

a) Undeformed (original) sample, b) A sample deformed at $220{ }^{\circ} \mathrm{C}$,

c) A sample deformed at $260{ }^{\mathrm{O}} \mathrm{C}$. 


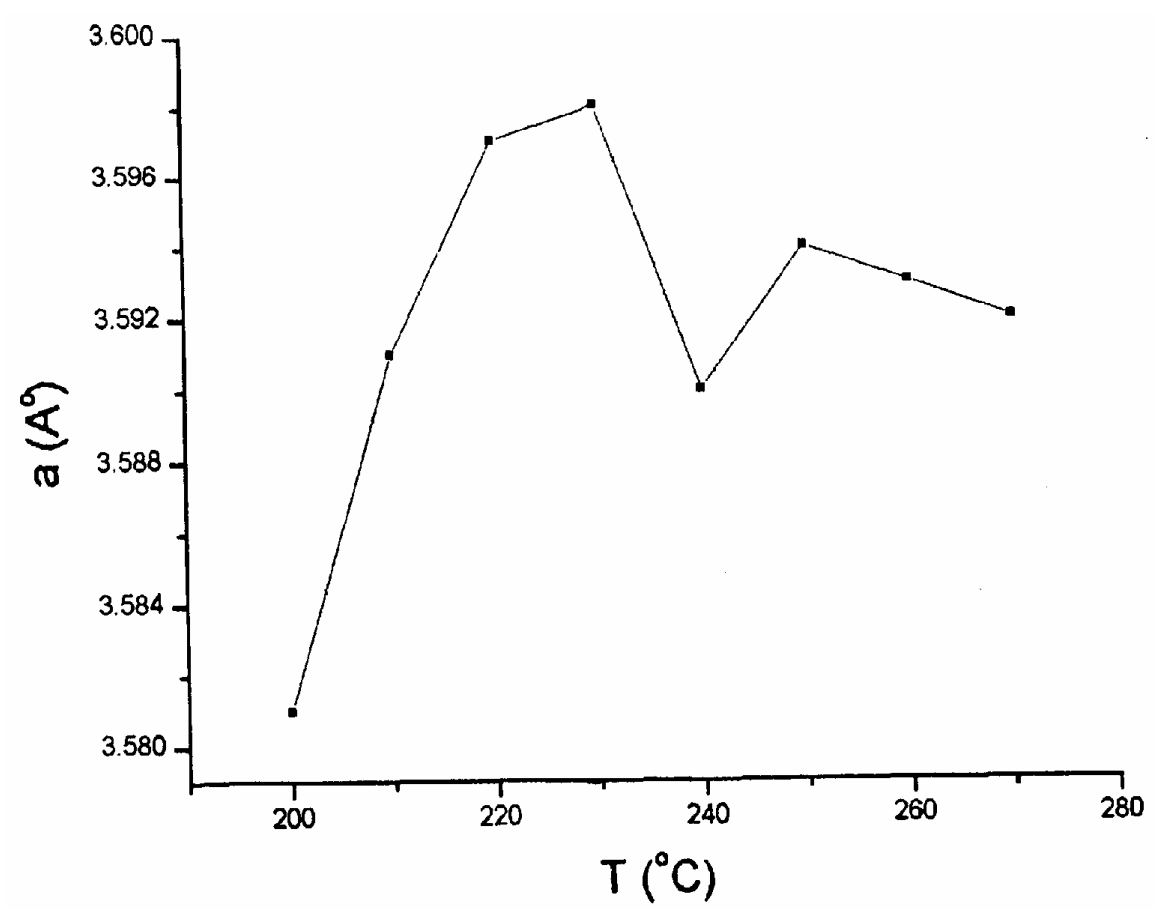

Fig.(8): The change in the lattice parameter, a, of the $\mathrm{Cu}$-phase with the working temperature.

The observed increase of the total tensile creep strain rate $\varepsilon_{\text {tot }}$ and the total recovery strain rate $\tau_{\text {tot }}^{*}$ with increasing temperature shown in Fig. $5 \mathrm{a}$, c is, therefore, considered as a result of the dissociation process of the $\varepsilon$-phase in the $\alpha$-matrix. Also, the increase in the homogeneity of the $\alpha$-phase and the homogeneity of the distribution of $\mathrm{Sn}$ atoms in the $\alpha$ - phase with increasing working temperature may contribute to the observed increase in the creep strain rate at higher temperatures.

The anomalous behaviour in transient creep in the temperature range 230- $250{ }^{\circ} \mathrm{C}$ is due to the transformation process occurring in the microstructural state of the alloy at temperature of $240{ }^{\circ} \mathrm{C}$ at which $\alpha+\varepsilon$ phases converted to a single solid solution $\alpha$ - phase, see the phase diagram of the $\mathrm{Cu}-\mathrm{Sn}$ system given in [14].

The transient creep parameters $\beta$ and $n$ increase extensively in the temperature range before their peak values, this observation may be due to the existence of the sample in the phase transformation region. This transformation is assured by the slowly movement of the $\varepsilon$-phase atoms in the $\mathrm{Cu}$-matrix at 
these low homologous temperatures. This transformation is also associated with a high concentration density of vacancies which increases with increasing temperature. The irregularity in the temperature sequence in the transformation temperature region leading to the anomalous behaviour of $\beta$ and $n$ values are, therefore, thought to be due to the redistribution and rearrangement of dislocations in the network at transformation temperature which lead to the formation of new Frank-Read sources [15].

The appearance of the logarithmic transient creep may be due to the multiplication of dislocations during transient creep stage leading to the formation of forest dislocations. In the low temperature range the particles of the intermetallic compound $\varepsilon$-phase cause some frictional forces to the dislocation motion in the $\mathrm{Cu}$-matrix. Meanwhile, in the high temperature range (above $240{ }^{\circ} \mathrm{C}$ ) the dissolution process of the $\varepsilon$-phase, thus, causing free $\mathrm{Sn}$ atoms which consequently move towards dislocation lines and hinder their motion. These processes prevent straining of the samples at these low homologous temperatures under the mentioned experimental conditions.

Increasing the working temperature increases the rate of the recovery processes, therefore the residual strain ratio, $\gamma$, decreases (see Fig 6a).

The activation energy of transient creep is calculated from the straight lines relating $\ln \left(\varepsilon_{\mathrm{tr}}\right)_{\mathrm{t}=1}$ and $10^{3} / \mathrm{T}$ (see Fig. 4). The present results yield activation energies 9.7 and $24.9 \mathrm{~kJ} / \mathrm{mol}$ in the low and high temperature ranges, respectively. The calculated value of the activation energy in the high temperature range is in agreement with the grain boundary sliding or migration [4]. The value of the activation energy in the low temperature range is about one third that in the high temperature range, which is suggested to indicate a dislocation mechanism.

The increase in the value of the lattice parameter of the Cu-phase ( $\alpha$ - phase) in the low temperature range is attributed to increasing the residual internal strains by the increase in the dissociation rate of the $\varepsilon$-phase. The decreasing in its value to minima at $240{ }^{\circ} \mathrm{C}$ (the transformation temperature) indicates the enhancement of the recovery processes, which causes the decrease in the residual strain ratio $\gamma$ (Fig. 6a). In the region above $250{ }^{\circ} \mathrm{C}$, its decreasing is due to the lowering of the internal lattice strains [16] as a result of the thermally activated process. 


\section{Conclusions:}

1- The X-ray diffraction patterns of the samples deformed in the low temperature range (below $240{ }^{\circ} \mathrm{C}$ ) for the $\mathrm{Cu}-2 \mathrm{wt} \% \mathrm{Sn}$ alloy, reveal the existence of the major $\mathrm{Cu}$-phase and the intermetallic compound $\varepsilon\left(\mathrm{Cu}_{3} \mathrm{Sn}\right)$ phase while those of the samples deformed in the high temperature range contain only the $\alpha$-solid solution phase.

2- The irregularity in the sequence of the transient creep curves in the temperature range $230-250{ }^{\circ} \mathrm{C}$, indicating a transformation process occurs in the microstructure of the used alloy.

3- The anomalous behavior of both $\beta$ and $n$ values is caused by the redistribution and rearrangement of dislocations in the network.

4- The observed decrease in the percentage residual strain ratio $\gamma$ is due to Increasing the rate of the recovery processes.

5- The activation energies of the transient creep below and above the transformation temperature characterize a dislocation mechanism and the grain boundary sliding or migration, respectively.

6- The decrease in the value of the lattice parameter of the $\mathrm{Cu}$-phase in the high temperature range is due to the lowering of the internal lattice strains by thermally activated process.

\section{References:}

1. V. Callcut and L. Brown, Welding and Metal Fabrication, 64, 3(1996).

2. M. Inaba, Y. Honma, K. Teshima, O. Hirao and T. Sakurai, Ttans. Jpn. Ins. Met., 28, 213 (1987).

3. G. Graiss, G. Saad, A. Fawzy and M. A. Kenawy, Czech. J. of Physics, 41, 149 (1991).

4. G. Saad, G. Graiss, A. Fawzy and M. A. Kenawy, Ind. J. Pure and Applied Phys., 29, 344 (1991).

5. A. Muto, K. Sato, S. Goto and M. Tagami, J. Japan Inst. Metals, 64 (5), 399 (2000).

6. C. M. L. WU and M. L. Huang, J. of Electronic Materials, 31, 442(2002).

7. M. R. Nagy, M. S. Sakr, M. M. Mostafa and R. Kamel; phys. stat. sol. (a), 88, 61(1985).

8. H. Orkawa and K. Sugawara, Scripta metall., 12, 83(1978).

9. Takao Endo and Norikazu Marumo, Transactions of the Japan Institute of Metals, 22, 848(1981).

10. M. M. Mostafa, G. S. Al-Ganainy, M. S. Abd El-Khalik and R. H. Nada, Physica B, 336, 402 (2003).

11. V. K. Semenchenko, "Surface Phenomena in Metals and Alloys", Pergamon Press, London, 1961.

12. G. S. Al-Ganainy, Egypt. J. Sol., 18, 345 (1995). 
13. A. A. El-Daly, A. M. Abdel-Daiem and M. Yousf, Materials Chemistry and Physics, 71, 111 (2001).

14. R. A. Higgins, "Engineering Metallurgy, Part 1; Applied Physical Metallurgy", Richard Clay (The Chaucer Press) Ltd, Bungag, Suffolk 400 (1983).

15. F. Abd El-Salam, M. M. Mostafa, M.M. El-Sayed, and R. H. Nada, phys. stat. sol.(a), 144, 111 (1995).

16. G. S. Al-Ganainy, M. T. Mostafa and M. R. Nagy, phys. stat. sol. (a), 165, 185 (1998). 